\title{
Investigation of Characteristics and Behavior of Loaded Carboplatin on the, Liposomes Nanoparticles, on the Lung and Ovarian Cancer: An In-Vitro Evaluation
}

\author{
Majid Hasanzadegan Roudsari ${ }^{1}$, Nasim Saeidi ${ }^{2}$, Nahid Kabiri ${ }^{3}$, Afrooz Ahmadi ${ }^{4}$, \\ Maral Mazloumi Tabrizi ${ }^{4}$, Hasan Ebrahimi Shahmabadi ${ }^{5}$, Azim Akbarzadeh \\ Khiyavi $^{6}$, Behnaz Reghbati ${ }^{7}$
}

${ }^{1}$ Department of Chemical Engineering, Science and Research Branch, Islamic Azad University, Tehran, Iran. ${ }^{2}$ Department of Medical Genetic, International Campos, Shahid Sadoughi University of Medical Science, Yazd, Iran. ${ }^{3}$ Gratuated from Veterinary Medicin, Shahid Chamran University of Ahvaz, Iran. ${ }^{4}$ Department of Toxicology and Pharmacology, Faculty of Pharmacy, Pharmaceutical Sciences Branch, Islamic Azad University, Tehran, Iran. ${ }^{5}$ Department of Microbiology, Parasitology and Immunology, Faculty of Medicine, Rafsanjan University of Medical Sciences, Rafsanjan, Iran. ${ }^{6}$ Department of Pilot Nanobiotechnology, Pasteur Institute of Iran, Tehran, Iran. ${ }^{7}$ General Biology Payam Noor University of Bahar, Iran.

\begin{abstract}
Introduction: Carboplatin is a chemotherapy drug which is used against some forms of cancer such as ovarian and lung carcinoma. This research was investigated to optimize and assess the Cytotoxicity of carboplatin Nanoliposomes on ovarian and lung cancer cell lines. Methods: Nanoparticles were prepared using reverse phase evaporation technique and characterized for light microscopy, spectrophotometry and drug-release properties. In the next step, A2780S and A2780CP (ovarian) and TC1 (lung) cell lines were used to determine the rate of Nano liposomal carboplatin cytotoxicity. Results: In this research, size and zeta potentials are $244.3 \pm 16.7 \mathrm{~nm}$ and $22.9 \pm$

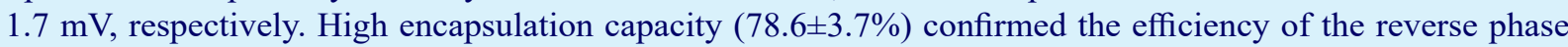
evaporation technique. The cytotoxic effect of this Nano liposome on all cell lines was significantly increased when compared with the free drug $(\mathrm{P}<0.05)$. Discussion: Our findings suggest that carboplatin liposomal Nanocarriers could serve as alternative chemotherapy modality for ovarian and lung cancer therapy.
\end{abstract}

Keywords: Carboplatin- nano liposomes nanoparticle- lung and ovarian cancer

Asian Pac J Cancer Biol, 1 (1), 9-13

\section{Introduction}

According to previous data, between various diseases including diabetes, metabolic syndrome and infectious diseases etc [1-5], cancer has considerable significance [6-7]. Nanoparticles have numerous applications in the fields of medicine and industry [8-9]. Diverse nanoparticles are applied in drug delivery, for example, liposomal nanoparticles,Niosomal nanoparticles and etc [10-13]. One the other hand, a more common treatments for cancer are the usage of chemotherapy and herbal agents [12-17] which may be improved (their effects) by nanotechnology. One of the most important anticancer
Submission Date: 01/13/2016 Acceptance Date: 02/25/2016

drugs is carboplatin, which is used to treat many types of solid cancer [16]. Carboplatin is a platinum-based anticancer drug that covalently binds to DNA to form DNA-platinum adducts and induces apoptosis of cancer cells [17]. This drug, similar with the other anticancer drugs, has a narrow therapeutic index, as its clinical use is hampered by a lot of unfavorable adverse effects, consisting of myelosuppression and more common thrombocytopenia [18]. Thus, much endeavor has been made to target carboplatin to cancer tissues, improving carboplatin's efficacy and safety. Recently, a lot of works have been conducted to develop a delivery system by changing the process to control the destiny of drugs,

\footnotetext{
Corresponding Author:

Behnaz Reghbati

General Biology Payam Noor University of Bahar, Iran.

Email: B_reghbati@yahoo.com
} 
particularly drug distribution within the organism. Liposome nanoparticles loaded with anticancer agents can capillary endothelial cells, the distance between nascent tumor from normal tissue penetration much easier and then quits tumor. It can cause the increase of natural anti-cancer drug concentration in the tumor and subsequently decrease its toxicity in normal tissues [19-20]. A variety of delivery systems to improve performance, carboplatin has been developed. For example, it's using biodegradable polymer nanoparticles [20], sodium alginate nanoparticles [21], Chitosan [22], solid lipid nanoparticles [23], Liposomes [24], silica nanoparticles [25], as drug nanoparticles have been extensively employed for the enhancement of efficiency.

Different carriers have been used for delivering carboplatin, but researchers have yet to be successful in producing the appropriate Nano liposome formulation from carboplatin. In this research, carboplatin Nanoliposomes were optimized, and their toxic effects were assessed on against various malignancies such as ovarian and lung carcinoma.

\section{Materials and Methods}

\section{Nano liposomal drug preparation}

Liposomal nanoparticles were synthesized using the reverse phase evaporation method. Briefly, approximately $7 \mathrm{mg}$ of carboplatin with $125 \mathrm{mg}$ of lecithin, $46 \mathrm{mg}$ of cholesterol and $50 \mathrm{mg}$ of polyethylene glycol (PEG3350) were mixed in $50 \mathrm{ml}$ of ethanol $96 \%$ by heating in $37^{\circ} \mathrm{C}$, $60 \mathrm{~min}$ at $150 \mathrm{rpm}$. After perfect dissolving, the solvent was separated using a rotary (Heidolph, Germany) in $37^{\circ} \mathrm{C}$, $140 \mathrm{~min}$ at $130 \mathrm{rpm}$. The achieved Gel layer was dissolved in Phosphate Buffer Saline ( $\mathrm{pH} 7.4,10 \mathrm{M}$ ), which was added two times. In that layer the final concentrations of carboplatin, lecithin, cholesterol, and PEG3350 were estimated $0.56 \mathrm{mg} / \mathrm{ml}, 10 \mathrm{mg} / \mathrm{ml}, 3.6 \mathrm{mg} / \mathrm{ml}$ and $4 \mathrm{mg} /$ $\mathrm{ml}$, respectively. Finally, the formulations were sonicated for 4 min using an ultrasonic bath (Bandelin Sonorex Digitec, Germany).

\section{Characterization of liposomes}

One milligram of the formulation was mixed in $2 \mathrm{ml}$ of PBS. After the determining of its absorption in $633 \mathrm{~nm}$, the zeta potential and mean diameter of the Nanoliposomes were measured using a Zeta sizer (Nano ZS3600, Malvern Instruments, UK). PEGylated Nano liposomal containing carboplatin was evaluated for the morphological point of view and probable crystallization using light microscopy (Nikon, Tokyo, Japan).To determine the rate of the entrapped drug, $36.5 \mathrm{mg}$ of the formulation were centrifuged $\left(60 \mathrm{~min}\right.$ at $4^{\circ} \mathrm{C}$ and at $\left.21,000 \mathrm{rpm}\right)$. Then, optical absorbance of the supernatant of each formulation was measured at $220 \mathrm{~nm}$ using a spectrophotometer (UV1800, Shimadzu Co). Encapsulation efficiency and the rate of drug loading were calculated by using Formulas 1 and 2 , respectively.

$$
\text { Encapsulation }(\%)=\frac{\text { The amount of drug in nanoparticle }(\mathrm{mg} / \mathrm{ml})}{\text { The amount of drug fed initially }(\mathrm{mg} / \mathrm{ml})}
$$

(Formula 2):

Drug loading $(\%)=\frac{\text { The amount of drug in nanoparticle }(\mathrm{mg} / \mathrm{ml})}{\text { Weight of nanoparticle }(\mathrm{mg} / \mathrm{ml})} \times 100$

Also, the stability of nanoparticles was evaluated in which particles were the nanoparticles produced by this method, after Lyophilization, were suspended again and Zeta sizer devices in terms of size and zeta potential were examined and were lyophilized than before. The results of the cytotoxicity of the first day were compared with it's of the second month after the MTT assay.

\section{In vitro study of produced Nanoformulation release}

In order to study the release of Nanocarrier carboplatin, $36.5 \mathrm{mg}$ of the drug liposomal suspension was poured in the dialysis membrane with Cut off: 10,000 D and suspended in $80 \mathrm{ml}$ of PBS (pH 7.4,10M) and stirred at laboratory temperature for 48 hours at $140 \mathrm{rpm}$. Then, $2 \mathrm{cc}$ of old PBS was out and combined with $2 \mathrm{cc}$ of fresh PBS at different times. The optical absorbance of the samples was determined at $220 \mathrm{~nm}$, and after the calculation of the free carboplatin concentration in each time by using the calibration curve, the release profile versus time ( 48 hours) was plotted.

\section{Cytotoxicity assay}

Cytotoxicity test was made by MTT assay on A2780S, A2780CP and TC1 cell line. Cells were cultured in per each well of 96 a density of $1 \times 10^{4}(10,000)$ cells and cultivated $\left(37^{\circ} \mathrm{C}\right.$ under $5 \% \mathrm{CO}_{2}$ and $90 \%$ humidity) in RPMI-1640 supplemented containing fetal bovine serum $(10 \%)$, penicillin $(0.2 \mathrm{mg} / \mathrm{ml})$ and streptomycin $(0.12 \mathrm{mg} / \mathrm{ml})$ antibiotics. After they were allowed to attach for $24 \mathrm{~h}$, the medium was removed and this process was repeated after another 24 hours. MTT solution (with a molar ratio of $4 \mathrm{mM}$ ) was attached into each well for $3 \mathrm{~h}$. Cells were treated with free drug and liposomal carboplatin different $(0.0087,0.0175,0.035$, $0.052,0.07,0.14,0.28,0.56,1.12,2.24$ and $4.48 \mu \mathrm{g} / \mathrm{ml})$ concentrations. Viability was evaluated during $48 \mathrm{~h}$ incubation. The absorbance $(570 \mathrm{~nm})$ was measured by the plate reader (Synergy Multi-Mode Elisa Reader, BioTek, USA). In vitro viability percent was investigated by following formula3.

\section{(Formula 3):}

$$
\text { Cell Viability precent }=\frac{A b s(\text { Sample })}{A b s(\text { control })}
$$

Finally, $\left(\mathrm{IC}_{50}\right)$ was calculated by using the statistical package Pharm-PCS program.

\section{Statistical analysis}

Results are expressed as mean $\pm \mathrm{SD}$. The data value from three separate tests that examined duplicates. The significance level was set at $\mathrm{P}$ values $<0.05$. 


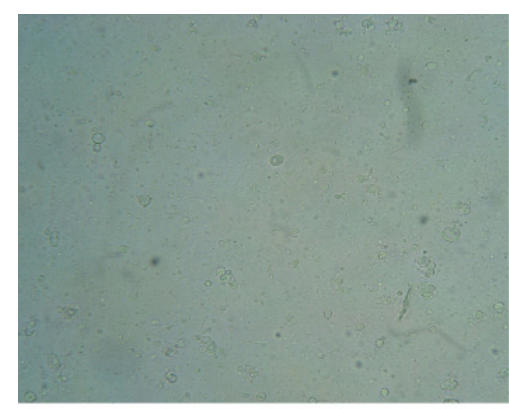

Figure 1. Light Microscopy of Carboplatin Loaded on Pegylated Liposomal Nanoparticles

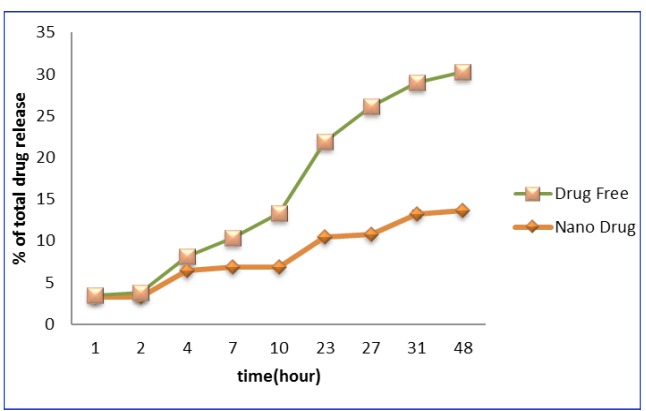

Figure 3. Release of Carboplatin From Carboplatin Nano Liposomes

Table 1. Prepared Materials for the Manufacture of Nanoparticles

\begin{tabular}{lcc}
\hline Number & Material & Source \\
\hline 1 & Carboplatin & Kunming Precious Metal Institute (Kunming, Yunnan, and China) \\
2 & Cholesterol & Sigma-Aldrich Co. (UK) \\
3 & Polyethylene glycol 3350 (PEG 3350) & Kimyagaran Emrooz Chemical Ind. Co. (Iran) \\
4 & Lecithin & Acros Co. (Belgium) \\
5 & RPMI 1640 & Gibco Co., Germany \\
6 & A2780S, A2780CP and TC1 cell line & Iran Pasteur Institute cell bank \\
\hline
\end{tabular}

Table 2. Characteristics (Stability) of Carboplatin Nano Liposomes

\begin{tabular}{lcc}
\hline Formulation & Zeta potential $(\mathrm{mV})$ & Size $(\mathrm{nm})$ \\
\hline Before Lyophilization & $-22.9 \pm 1.7$ & $244.3 \pm 19.6$ \\
After Lyophilization & $-24.3 \pm 1.9$ & $254.3 \pm 21.7$ \\
\hline
\end{tabular}

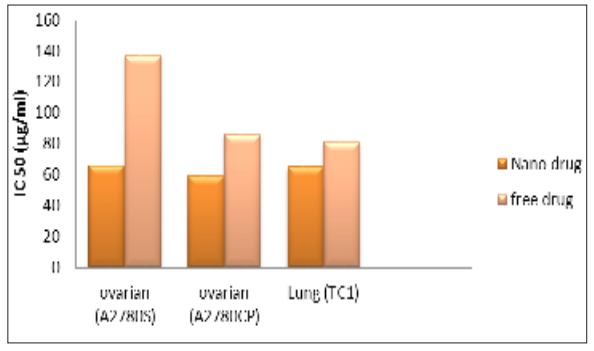

Figure 2. $\mathrm{IC}_{50}$ Value of Carboplatin Formulation Loaded on Nanoparticle Liposome, Two Months after Production

\section{Results}

\section{Characterization of liposomes}

The mean size of Nano liposomal carboplatin, the potential of zeta was found to be $244.3 \pm 19.6 \mathrm{~nm}$ and $-22.9 \pm 1.7 \mathrm{mV}$, respectively. Light microscopy confirmed preparation of nanoparticles with spherical to ellipsoid hallow forms dispersed throughout the matrix (Figure 1). According to Formulas 1 and 2, the encapsulation efficiency and drug loading contents were calculated $78.6 \pm 3.7 \%$

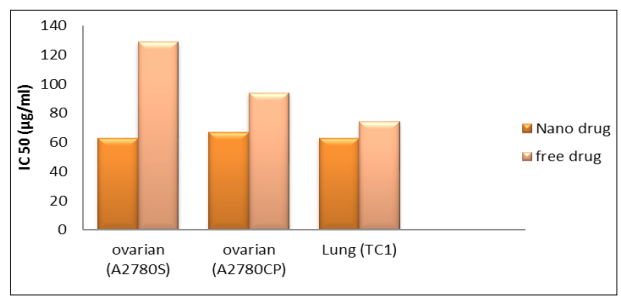

Figure 4. A Comparison betweenic 50 Values of Carboplatin and its Nano Liposomal Formulation in the Three Cell Lines, A2780CP, A2780S And TC ${ }_{1}$.

and $2.5 \pm 1.1 \%$, respectively. Other views, $78 \%$ of the used drug become associated with Nanocarriers and carboplatin accounts for $2.5 \%$ of nanoparticles weight. In addition, results of size, zeta potential after lyophilized nanoparticles (Table 2) and assay MTT after 2 months were confirmed the proper stability of nanoparticles (Figure 2).

\section{Drug release study}

As shown in Figure 3, carboplatin released from the Nanoliposomes to PBS was measured during time intervals of $1,2,4,7,10,23,27,31$, and 48 hours using the standard curve of carboplatin. Regarding the nanoparticle, release the drug curve initiated with a burst release $(27 \%$ encapsulated capacity of drug) followed by the mild ascending slope with the maximal release of $16.4 \%$ after $48 \mathrm{~h}$. In contrast, the standard drug was shown

Table 3.The Cytotoxicity of These Formulations During Production and Two Months after Production

\begin{tabular}{lcccccc}
\hline \multirow{2}{*}{ Time } & \multicolumn{2}{c}{$\mathrm{A} 2780 \mathrm{~S}$} & \multicolumn{2}{c}{$\mathrm{A} 2780 \mathrm{CP}$} & \multicolumn{2}{c}{$\mathrm{TC} 1$} \\
& $\mathrm{IC}_{50}$ & $\mathrm{IC}_{50}$ & $\mathrm{IC}_{50}$ & $\mathrm{IC}_{50}$ & $\mathrm{IC}_{50}$ & $\mathrm{IC}_{50}$ \\
& $\mathrm{NL}-\mathrm{CP}$ & $\mathrm{F}-\mathrm{CP}$ & $\mathrm{NL}-\mathrm{CP}$ & $\mathrm{F}-\mathrm{CP}$ & $\mathrm{NL}-\mathrm{CP}$ & $\mathrm{F}-\mathrm{CP}$ \\
\hline Production time & $63.1 \pm 22.7$ & $128.8 \pm 51.8$ & $57.5 \pm 6.0$ & $77.6 \pm 16.7$ & $63.3 \pm 14.4$ & $74.6 \pm 11.1$ \\
2 months after production & $66.4 \pm 18.5$ & $137.2 \pm 33.4$ & $59.4 \pm 7.2$ & $86.2 \pm 19.1$ & $65.4 \pm 15.3$ & $81.4 \pm 12.7$ \\
\hline
\end{tabular}


faster release pattern in which $33 \%$ of the standard drug was found into PBS.

\section{Cytotoxicity assay}

As shown in Figure 4, results showed experimental data for $\mathrm{IC}_{50}$ values on all mention cell lines. Cell viability was significantly decreased in a dose-dependent manner after exposure of cancer malignancies (lung and ovarian) cell lines to free carboplatin and its Nano liposomal formulation using the MTT assay. The experimental data for $\mathrm{IC}_{50}$ (Production time and 2 months after production) values on the ovarian and lung cell lines are summarized in Table 3.

\section{Discussion}

Nanocarriers construction by biodegradable materials provide the possibility of drug release over a period of several days or even weeks and small size of Nanocarriers make them penetrate into target cells through tiny capillaries, two basic features of Nanocarrier drug delivery systems [26]. High encapsulation capacity confirmed the reverse phase evaporation method is a preparation of PEGylated Nano liposomal containing carboplatin. PEG was used in the nanoparticles because of improving the stability of liposomal nanoparticles in the blood circulation, water-soluble polymer, low immunogenicity, and antigenicity and is able to extend the time of low drug-release properties [27]. Nanocarriers were found Unilamellar Vesicles (ULVs) that may result from sonication effects. There is a direct relationship between the zeta potential of nanoparticles and suspension stability [28]. Zeta potential of $-22.9 \mathrm{mV}$ confirmed the proper stability of particles. In a study, the roles of various drugs with Nano liposomal formulations were evaluated in different cell lines. For instance, Zhang et al. [29] investigated the cytotoxicity effect of PEGylated (PEG2000) Nano liposomal containing carboplatin against gastric cancer with the thin film hydration method. They were used diverse materials (PEG molecular weight was diverse and etc.) compared to our study in which our materials were cheaper. The in vitro results of the study showed that the cytotoxic effects of Nano liposomal carboplatin increase when compared with free carboplatin. In the present study, the stability of Nanoliposomes was confirmed 2 months after production, by MTT assay and its Lyophilization and then carboplatin release kinetics were studied in vitro. In the formulation showed that carboplatin release kinetics results showed an initial burst of drug release during the second 2 hours and then a slowed release pattern until 10 hours and a sustained release for 27 hours. The initial burst of drug release suggests that some of the drugs was localized on the surface of the Nanoliposomes because of defect capsulation, and later the sustained release was due to the release of the drug from the cross-linkage site of the Nanoliposomes.

The comparison between the cytotoxicity effects of the Nano liposomal carboplatin with free drug shows the higher efficiency of Nano liposomal carboplatin in destroying mention all cell lines. This may be because the Nano liposomal carboplatin has a phospholipid structure like the bilayer structure of an ovarian and lung cell lines membrane and can better penetrate to these cells and there is a direct relationship between drug release and death in these cells with entering the goal cell [30]. Among these, the A2780S $(\mathrm{P}<0.01)$ cell line was more sensitive than the $\mathrm{A} 2780 \mathrm{CP}(\mathrm{P}<0.05)$ cell line to liposomal nanoparticle effects, which may be a result of the difference between genotype and/or membrane structure in the ovarian cell lines that were studied [31].

Taking collectively, our research confirms that Nano liposomal carboplatin has more cytotoxic effects than free carboplatin on ovarian and lung cancer cell lines. Thus, this formulation may be an alternative chemotherapeutic candidate for ovarian and lung cancer in the future.

\section{References}

1. Ebrahimi Far M, Mazdapour M, Kaki A, Mohammadi P, et al . Comparison of Biochemical Factors and Liver Enzymes in type 2 Diabetes Patients and Healthy Individuals. Bull EnvPharmacol Life Sci, 2015. 4, 1-4.

2. Goodarzi MT, Mohammadian M, BorzoueiSh,et al . Association between Plasma Cholesteryl Ester Transfer Protein activity and Lipid profiles in Metabolic Syndrome in an Iranian Population.Int Res J Biological Sci, 2014..3;8990 .

3. Mohammadian M, ToofaniMilani A, Hassas M R,et al . Evaluation of Serum Iron, Zinc and Their Relationships with Glycemic Control Status in Iranian Elderly Women with Type 1 Diabetes Mellitus. Journal of Pharmacy and Pharmacology,2015. 3;411-416.

4. Rostamzadeh Z, Mohammadian M, Rostamzade A. Investigation of Pseudomonas aeruginosa Resistance Pattern against Antibiotics in Clinical Samples from Iranian Educational Hospital. Adv Microbiol; 2016.6(3),190-194.

5. RostamzadehKhameneh Z, Mohammadian M, Nemati M, Rostamzade A. Investigation of Herpes Simplex Virus-2 (Hsv-2) Infection in Coronary Artery Disease Patients (CAD) in Population from Iran. Advances in Bioresearch. 2015.6,74-78.

6. Mohammadi H, Abedi A, et al. Evaluation of synthesized platinum nanoparticles on the MCF-7 and HepG-2 cancer cell lines, International Nano Letters, 2013, vol. 3, no.1, p 1-5.

7. Khalili M, Akbarzadeh A, et al. The effect of nanoliposomal and PE gylated nanoliposomal forms of 6-gingerol on breast cancer cells, Research Journal of Recent Sciences, 2009, vol. 2277, p. 2502.

8. Esfahani MKM et al. Pegylation of nanoliposomal paclitaxel enhances its efficacy in breast cancer, Tropical Journal of Pharmaceutical Research, 2014, vol. 13, no. 8, p. 1195-1198.

9. Izadi M, Ebrahimi Far M, Kanaani L, et al. Remove Nickel (II) From Drinking Water Using Thiol-Functionalized Chitosan. Advanced Biomedical Research, 2016. 7, 107-112.

10. Izadi M, Ebrahimi Shahemabadi H, Kanaani L, et al (2016). Investigation of characteristics of loaded carboplatin on the liposomal nanoparticles on the cell carcinoma of the human brain c6. Adv. Biores, 7, 113-118.

11. Poy D, Akbarzadeh A, EbrahimiShahmabadi H, et a. Reparation, Characterization and Cytotoxic Effects of LiposomalNanoparticles Containing Cisplatin: An in Vitro Study. Chemical Biology \& Drug Design,2016. 88, 568-573.

12. Ahmadi L, Chiani M, et al. To evaluate the effect of 
formulation of Nanoarchaeosomal 6-gingerol on the growth of breast cancer MCF-7 cell line, New Cellular and Molecular Biotechnology Journal, 2015, vol. 5, no. 19, p 47-52.

13. Amiri B, Ebrahimi Far M, Saffari Z, et al. Preparation, Characterization and Cytotoxicity of Silibinin Containing Nanoniosomes in T47D Human Breast Carcinoma Cells. Asian Pac J Cancer Prev, 2016.17, 3833-3836.

14. Rostaminasab S, Toofani Milani A, Mohammadian M, et al . Antitumor Immunostimulatory Effect of Sitosterol from Salvia atropatana on Tumor bearing mice. Adv Biores, 2015. 6, 133-40.

15. Sajjadiyan SZ, Toofani Milani A, Mohammadian M, et al. Preparation of silibinin loaded pegylatedniosomal nanoparticles and investigation of its effect on MCF-10A human breast cancer cell line. Der Pharm Lett, 2016. 8, 70-5.

16. C. Della Pepa, G. Tonini, C. Pisano, M. Di Napoli , S.C. Cecere, R. Tambaro, G. Facchini,S. Pignata.Chin J Cancer. 2015. 34, 1, 17-27.

17. Y. Ando, T. Shimokata, Y. Yasuda, Y. Hasegawa. Nagoya J Med Sci. 2014, 76, (1-2), 1-9.

18. A. Schmitt, L. Gladieff, C.M. Laffont,A. Evrard, J.C. Boyer , A. Lansiaux,C. Bobin-Dubigeon, M.C. Etienne-Grimaldi, M. Boisdron-Celle , M. Mousseau, F. Pinguet,A. Floquet, E.M. Billaud, C. Durdux, C. Le Guellec, J. Mazières, T. Lafont, F. Ollivier, D. Concordet,E. Chatelut. J ClinOncol. 2010, 28, 30, 4568-4574.

19. X. Zhang, H. Yang, K. Gu, J. Chen, M. Rui, G.L. Jiang. Int J Nanomedicine. 2011, 6, 437-444.

20. Sadhukha T, Prabha S. Encapsulation in nanoparticles improves anti-cancer efficacy of carboplatin. AAPS PharmSciTech. 2014 Aug;15(4):1029-38. doi: 10.1208/ s12249-014-0139-2. Epub 2014 May 16.

21. Basavaraj K. Nanjwade, Jeet Singh, Kemy A. Parikh, F.V. Manvi. Preparation and evaluation of carboplatin biodegradable polymeric nanoparticles. International Journal of Pharmaceutics. Volume 385, Issues 1-2, 29 January 2010, Pages 176-180.

22. Fu-Rong Li, Wen-Hui Yan, Yue-Hua Guo, Hui Qi\&Han-Xin Zhou. Preparation of carboplatin-Fe@C-loaded chitosan nanoparticles and study on hyperthermia combined with pharmacotherapy for liver cancer. International Journal of Hyperthermia. Volume 32, Issue 2, 2016.

23. V. Sankar, Shalini Devi Penmetsa and C Sabarinath. Folate Conjugated Solid Lipid Nanoparticles of Carboplatin for Targeting Cancer Cells. Drug Delivery Letters, 2(3): 162170 .

24. Chaudhury A et al. Potent therapeutic activity of folate receptor-targeted liposomal carboplatin in the localized treatment of intraperitoneally grown human ovarian tumor xenograft. Int J Nanomedicine. 2012;7:739-751.

25. Scodeller P, Catalano PN, Salguero N, Duran H, Wolosiuk A, Soler-Illia GJ. Hyaluronan degrading silica nanoparticles for skin cancer therapy. Nanoscale. 2013 Oct 21;5(20):9690-8.

26. Andrieux K \&Couvreur P (2009) Wiley Interdiscip Rev NanomedNanobiotechnol 1, 463-474.

27. Shahbazian S, Akbarzadeh A, Torabi S \&Omidi M (2015) Biotechnol Lett.37, 1355-1359.

28. Honary S \&Zahir F (2013) Trop J Pharm Res 12, 265-273.

29. Zhang $J$ et al. Antitumor and antimetastasis effects of carboplatin liposomes with polyethylene glycol-2000 on SGC-7901 gastric cell-bearing nude mice.Oncol Lett 2014;8(5):2209-2214.

30. M, Slingerland, H.J. Guchelaar, H. Gelderblom. Drug Discov Today. 2012, 17, 3-4, 160-166.

31. S. Domcke, R. Sinha, D.A. Levine, C. Sander, N. Schultz. Nat Commun.2013; 4, 2126.1-10.

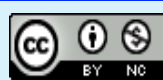

This work is licensed under a Creative Commons AttributionNon Commercial 4.0 International License. 